$9-1-2020$

\title{
A case study of OVC Case Management through the Zambia Family (ZAMFAM) project-Brief
}

Population Council

Follow this and additional works at: https://knowledgecommons.popcouncil.org/departments_sbsr-hiv

Part of the Family, Life Course, and Society Commons, and the Maternal and Child Health Commons How does access to this work benefit you? Let us know!

\section{Recommended Citation}

Population Council. 2020. "A case study of OVC Case Management through the Zambia Family (ZAMFAM) project," technical brief. Lusaka: Population Council. 


\section{A CASE STUDY OF OVC CASE MANAGEMENT THROUGH THE ZAMBIA FAMILY (ZAMFAM) PROJECT}

The 2018 Zambia Demographic and Health Survey estimates Zambia's HIV prevalence at 11.1\% among adults aged $15-49$ years and $1.1 \%$ among children aged $<15$ years (1). The Zambia National HIV/AIDS/STI/TB Council estimates that 10\% (over 1.3 million children under age 18 years) of Zambia's population are vulnerable or at high risk of being orphaned due to the impact of the HIV pandemic (2). Since the epidemic began, an estimated 250,000 children and adolescents have already been orphaned in Zambia as a result of HIV/AIDS (3).

The United States Agency for International Development (USAID) through the President's Emergency Plan for AIDS Relief (PEPFAR) has been supporting the Zambia Family (ZAMFAM) program since 2015 . The ZAMFAM program (implemented in Lusaka and Chingola) aims is to improve care and resilience of orphans and vulnerable children (OVC) as well as young people living with HIV (YPLHIV) by providing support and protection and by strengthening the capacity of children, families and the community to better manage the socio-economic shocks of the HIV/AIDS epidemic.

As the project comes to an end in 2020, ECR engaged Population Council to conduct a qualitative case study of the ZAMFAM program. A case study approach was employed to understand actors, perceptions and document best practices by ZAMFAM program. This brief summarizes case study findings.

\section{ZAMFAM PROGRAM}

The ZAMFAM program utilized several approaches to improving the wellbeing of OVC. The bedrock of the

${ }^{1}$ The OVC Case Management Approach in the ZAMFAM program provided a structured approach to child protection and response and helped reduce the risk of harm to a child. OVC Case Management encompassed the planning, implementation and monitoring of assistance that was deemed appropriate to a case until the situation improved or was resolved. This approach further involved coordinating delivery of services in the community. (Catholic Relief Services. 2017. Case Management for Children Orphaned or Made Vulnerable by HIV. PEPFAR.) program was the OVC Case Management Approach ${ }^{1}$ that was used. Services or referrals were provided to beneficiaries through home visitation or one-stopshops and were delivered by trained community volunteers (CVs) who came from faith/communitybased organizations (F/CBOs) sub-granted by the ZAMFAM Program. The services provided to OVC and their caregivers included psychosocial support, child protection, food and nutrition, HIV prevention, HIV care and support, education support, health and economic strengthening and referrals were made to health facilities for additional HIV counseling services.

These trained CVs also helped identify OVC that needed educational support, which included the payment of school fees and provision of school supplies like books. CVs educated communities about child protection and nutrition, worked with health facilities to support antiretroviral therapy (ART) uptake and adherence in addition to making referrals to other services or resources as appropriate. CVs provided these services through one-stop-shops and household visits and used a case management approach to track cases and ensure that OVC needs were being met.

ZAMFAM also provided trainings for caregivers of OVC addressing ART adherence, parenting skills, economic strengthening and nutrition for children and YPLHIV. OVC were given life skills training and received sexual reproductive health talks during youth and adolescent clubs. ZAMFAM also helped communities establish community savings groups (CSGs) and, under the Public Private Partnerships (P3) Initiative, connected these groups with farming food and supplies. These were necessary for reaching program objectives and meeting the households' and beneficiaries' needs.

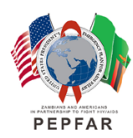




\section{OBJECTIVES}

The goal of the case study was to better understand actors, perceptions, and document best practices by ZAMFAM program, especially as it relates to the how the program affected OVC and their households. The case study was intended to identify and document best practices as well as lessons learned. The objectives of the case study were:

1. To explore OVC and caregivers' views and perspectives on the services provided by ZAMFAM in the four main program domains including health, child protection, education and economic strengthening.

2. To explore ZAMFAM program effects on beneficiary households from the stakeholders' perspectives.

3. To better understand how the program was implemented and identify best practices.

\section{METHODOLOGY AND STUDY SUBJECTS}

Focus group discussions (FGD) and key informant interviews (KII) were conducted in two study sites (Lusaka and Chingola) between December 2019 and January 2020. A total of 12 FGDs were conducted with 58 OVC and 44 caregivers. Additionally, 14 KIls were

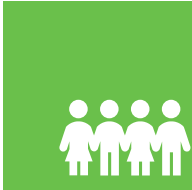

OVC

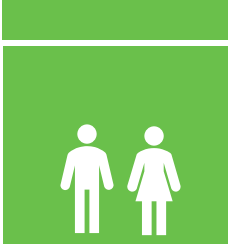

Caregivers

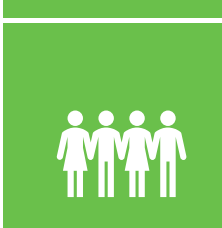

Stakeholders
OVC beneficiaries aged 13-17 were purposively sampled from ECR's program databases. FGDs were conducted separately by sex and by age group (13-14 and 1517).

Caregivers were aged 18+; currently providing care to a child (younger than 17 years); living in adverse conditions (HIV positive, chronically ill or orphaned); and the OVC either lived in their household or identified that person as their primary caregiver.

Respondents were conveniently sampled based on their levels of knowledge of the program as advised by ECR, F/CBOs, community volunteers, and government staff. conducted with stakeholders from Expanded Church Response (ECR), government ministries including the Ministry of Community Development and Social Services (MCDSS) and Ministry of Health ( $\mathrm{MoH})$, $\mathrm{F} / \mathrm{CBO}$, and local authorities. To gather information on best practices and lessons learned, we conducted a desk review of the ZAMFAM progress reports, success stories, and routine data from 2016 to 2019 recorded by ECR.

TABLE 1 Number of FGDs with OVC and caregivers and Klls with stakeholders

\begin{tabular}{|c|c|c|c|c|}
\hline District & $\begin{array}{l}\text { OVC age } \\
13-14 \\
\text { FGDs }\end{array}$ & $\begin{array}{l}\text { OVC age } \\
15-17 \\
\text { FGDs }\end{array}$ & $\begin{array}{l}\text { Caregivers } \\
\text { aged 18+ } \\
\text { FGDs }\end{array}$ & $\begin{array}{l}\text { Stakeholder } \\
\text { KIls }\end{array}$ \\
\hline Lusaka & 2 & 2 & 2 & 6 \\
\hline Chingola & 2 & 2 & 2 & 8 \\
\hline
\end{tabular}

\section{KEY FINDINGS}

This brief summarizes key findings per study objective.

\section{OBJECTIVE 1 \\ To explore OVC and caregivers' views and perspectives on the services provided by ZAMFAM in the four main program domains (health, child protection, education, and economic strengthening).}

\section{High knowledge of HIV acquisition, testing and treatment among beneficiaries}

The study found that knowledge of HIV transmission and testing services was high, and respondents linked this to the HIV prevention training and home-based HIV testing services. During home visits, beneficiaries reported that community volunteers provided information on HIV prevention, care, and treatment.

OVC across the study sites were able to show their understanding of how HIV is acquired, transmitted and treated. OVC identified using condoms, having one sexual partner, and getting an HIV test before starting a new sexual partnership as ways of reducing transmission.

\author{
"They [CVs] helped us a lot, like the \\ program of people knowing their [HIV] \\ status. There were self-testing kits, as you
}


know some people feel uncomfortable to go and test from the clinic. That's how we were helped." - Male caregiver, Lusaka

"Safe sex is being safe from contracting diseases or having unplanned pregnancies. Use a condom if you don't want to contract diseases, use pills to prevent unplanned pregnancies and be faithful to one sexual partner to avoid contracting diseases like HIV/AIDS and syphilis." - Female OVC 15-17 years old, Chingola

\section{Program beneficiaries highly valued the psychosocial and emotional support of the ZAMFAM program}

As CVs conducted beneficiary home visitation, they provided counseling services, including child abuse counseling, psychosocial, and adherence counseling support. Beneficiaries highly valued the psychological and social support that OVC and caregivers received and felt that programing that caters to the psychosocial needs of OVC were essential to supporting vulnerable households.

Some of the respondents appreciated the counseling on child nutrition that helped them monitor the growth of their children and ensure they were healthy. Other participants mentioned that they appreciated the encouragements the CVs gave regarding ART adherence. Respondents identified receiving emotional support, as well as the reassurance that ECR would assist them if they encountered challenges as a useful component of the program.

"The moment they (CV) arrived at my home, I felt free to talk to them about what I was going through, including my health... This made it easy for us, even when we visited the clinic, because we did not have to stay on a queue. Instead, they would easily recognize us and attend to us." Female caregiver, Lusaka

\section{Caregivers felt support received from ZAMFAM in addressing child abuse and child labor was an important aspect of the program design}

Caregivers expressed knowledge on where to report when a child is abused, adding that CVs raised awareness on child protection on how to prevent and respond to violence against children, such as defilement, rape, and child labor. Caregivers were sensitized regarding the rights and responsibilities of children and how best to protect them from all forms of abuse. From FGDs with caregivers and OVC, it was noted that there was a lot of support available for victims of sexual gender-based violence at health facilities and that several F/CBOs had also joined in providing support.

"There are usually cases like that, but they
are not reported. At times we just hear
rumors and investigate because it's rare
that such cases are reported. When you
come across such a child, you refer them
to the hospital because this is where the
NGOs have opened up some centers in
hospitals and clinics where we can take
such cases. They have really been of help
in terms of counseling of gender-based
violence cases..." - Male caregiver,
Lusaka

\section{Community Savings Groups provided much needed financing for caregivers and their OVC needs}

Beneficiaries felt the economic strengthening programming was highly beneficial to their financial stability, but given the severity of their needs, they identified several challenges where greater support was needed. Through the use of CSG approaches, caregivers were encouraged to open saving groups that did not rely on the program for sustainability. CVs supported the formation of savings groups to ensure the households they served had access to credit if needed. Some caregivers reported having benefited from these savings groups in that they were able to mitigate financial risks by saving, borrowing money when they needed it, and repaying their loans on time. Caregivers relied on savings groups to meet their financial needs, including children's school fees, medical bills and 
establishing businesses. Additionally, these savings groups gave them an opportunity to share and exchange ideas, encouraging community interaction and cohesion.

"They have inspired us to be self-reliant by introducing savings groups to us. We can save money on our own." - Female caregiver, Chingola

"ZAMFAM has helped us to open these saving groups so that we don't rely on them entirely. Because they will not always be there, it's better to sustain ourselves. It's really necessary to be part of these groups..." - Male caregiver, Lusaka

\section{Beneficiaries greatly valued educational support, although more needed to be done}

Beneficiaries felt the educational support provided by ECR was instrumental in helping many children complete secondary school, though they noted the support provided was sometimes insufficient to meet demand. Both OVC and their caregivers frequently mentioned receiving educational support such as payment for school. Additionally, when discussing the services provided under the ZAMFAM program, respondents were most likely to talk about educational support benefits as opposed to the other support services. Some of the respondents reported that it was difficult for children in the communities to complete secondary schooling and as a result were forced to stay home due to inadequate resources at the household level. However, caregivers noted with the support received under ZAMFAM, their children were able to complete secondary education, while some OVC were sponsored to attend vocational training like carpentry or tailoring.

"They have been so much help. Before, you would find that a child makes it to grade 10 , but then due to lack of sponsorship they will just drop out. When ZAMFAM came in, most people were assisted to complete secondary school. Even school dropouts have been reached with tertiary education programs like carpentry, tailoring, and computer lessons." - Male caregiver, Lusaka

\section{Beneficiaries equipped to use local produce for maximum nutritional benefit}

Caregivers valued the nutritional education provided through ECR. Cooking demonstrations were conducted under the program and their main target groups were PLHIV, under-nourished children, children under five, and pregnant women. $\mathrm{MoH}$ growth monitoring teams incorporated some CVs to help monitor growth of children under five at community health facilities. Parents/caregivers also recalled that the cooking demonstrations emphasized how to prepare local foods in the most nutritious way. This knowledge was greatly appreciated, and caregivers reported that the nutrition program helped them take care of their children.

"The nutrition programs were also very helpful; they demonstrated using a wrapper which had colors like green, yellow and red. This was meant to show people how to monitor the growth of a child. Most people have children, but they don't know how to take care of them or what to feed them." - Male caregiver, Lusaka

\section{OBJECTIVE 2}

To explore stakeholders' views and perspectives on the ZAMFAM program

Stakeholders interviewed for the study provided perspectives that helped provide robust insight into how services were delivered, as they were instrumental to the program's operations. The views and perspectives of stakeholders are detailed below.

\section{Collaboration between ZAMFAM and government improved outcomes for HIV care and management as well as child protection}

Stakeholders observed the close working relationship between ZAMFAM and MoH improved access to HIV services and provided a wide range of support to YPLHIV and their families. The Ministry trained CVs in HIV testing and referrals to identify HIV positive OVC 
during home visits and refer them to the clinic for treatment. MoH provided test kits and information, education, and communication materials and ensured that referrals made by CVs received care. Stakeholders noted that CVs influenced ART adherence. Health talks were organized for YPLHIV and caregivers of HIV positive OVC to learn about the health needs of these children.

Additionally, stakeholders reiterated the importance of supporting the additional physical and psychosocial needs of YPLHIV. CVs were provided nutritional support services via cooking demonstration and growth monitoring. They also successfully formed support groups for HIV positive OVC and adults, which provided an opportunity for greater emotional support and information exchange.

\section{"We get a lot of support from Ministry of Health for trainers of community volunteers because we use their curriculum for training. They also provide the HIV testing kits and the personnel to conduct the test. We are able to refer children for treatment who we find positive. Since we have our volunteers attached in the health facilities, we are able to follow up with children missing appointments. Volunteers bring them to the facility where they are put back on treatment." - Stakeholder, Lusaka}

\section{ZAMFAM trainings equipped community volunteers to link OVC to full package of services required}

The recruitment and training of $\mathrm{CVs}$ was a collaborative effort between ECR, MoH, other line ministries, local F/CBOs, and health clinics. ZAMFAM identified and registered $\mathrm{CVs}$ in conjunction with $\mathrm{MoH}$ by utilizing registers from local F/CBOs. CVs were recruited to work in the area where they lived, and their familiarity with the community made program delivery logistics easier. ZAMFAM invested in trainings for community volunteers for full-service provision for beneficiaries. This resulted in OVC recruited under the program receiving care and support to match their needs. Stakeholders reported that CVs work with health facilities in ART, TB and under-five departments to help identify HIV positive
OVC/cases for CVs to follow up and ensure they receive the treatment and care required.
"The caregivers are identified and registered by the CBOs. Then we provide training to them on how they are supposed to identify the children and what type of care and the support they are supposed to provide to them. The curriculum we are using is the Ministry of Health curriculum." - Stakeholder, Lusaka

CVs were trained on tracing suspected loss to follow up and adherence support in addition to being trained to register HIV positive children at health facilities. Stakeholders observed how this training in conjunction with their knowledge of the community equipped CVs to be effective links between OVC and the services they needed.
"...you find that in the community they will find someone is HIV positive and refer that person to us as the [health] facility so that we initiate him/her on ART. There are also people in the community who start treatment but are suspected lost to follow- up. So [Organization X] has people that go into the community to trace clients lost to follow-up." - Stakeholder, Lusaka

\section{Livelihood improvement approaches had positive impacts on household economic resilience}

Key informants were also asked to share their perspectives on program approaches for improved livelihoods in the ZAMFAM Program. Stakeholders reported that the CSGs and economic trainings in managing savings and entrepreneurial skills had a positive impact on household economic resilience. ZAMFAM facilitated the transformation of saving groups into cooperatives and helped register the groups with the Ministry of Agriculture and MCDSS to ensure sustainability of interventions as the ZAMFAM Program is coming to an end. Stakeholders felt this helped secure the continued success of CSGs beyond the duration of the program. The program also linked caregivers to the social cash transfer scheme and to organizations that taught them how to utilize the money 
received. The social cash transfer scheme is a government program that provides in-kind cash transfers to under-resourced populations to promote quality social welfare services, reduce juvenile delinquency, and alleviate poverty.

"Some guardians [caregivers] are on the social cash transfer scheme with Community Development [MCDSS]. They were also linked to organizations where they were taught how to invest this money into businesses." - Stakeholder, Lusaka

\section{Stakeholder views on program challenges}

Stakeholders noted various challenges experienced in supporting or implementing the ZAMFAM program. The ZAMFAM program interventions relied on community volunteers to achieve program outputs, and while this approach contributed to many of the program's successes, most of the implementing organizations noted challenges with this. Stakeholders identified low literacy levels among volunteers as a challenge as it affected data quality for the program. Also, training CVs required significant investments of time, money, and resources by $\mathrm{F} / \mathrm{CBO}$, but not all trained volunteers remained active during the life of the program.

Additionally, some stakeholders observed that organizations began to compete for volunteers by raising reimbursement rates to attract greater interest. The competition and conflict between organizations working towards similar goals whilst relying on volunteer staff made it difficult for program implementation.

"...there is competition now in terms of monetary incentives, because they are not standardized. You may find that some organizations are giving their volunteers more money." - Stakeholder, Lusaka

\section{Sustainability of program interventions}

ECR worked closely with several stakeholders to engage ZAMFAM program beneficiaries in the sustainability of program interventions. Transition meetings were held with caregivers of OVC, CVs and key stakeholders in order to adequately plan for the sustainability of interventions. Stakeholders praised ZAMFAM's utilization of pre-existing community structures, noting that building the local capacity of $\mathrm{F} / \mathrm{CBO}$ s helped ensure that OVC continued to receive support after the program ended. Some respondents also applauded links established with government ministries like MCDSS, as this ensured ownership of program activities as well as data for future use by government.
"...sustainable in the sense that ZAMFAM
has been working within local structures.
The CBOs are based in the community. The
churches will always be there and will
continue to support children. ZAMFAM has
built their capacity so even if the project
comes to an end, they will continue
providing those services to the children.
Challenges would only exist for services
that require funds." - Stakeholder, Lusaka

\section{OBJECTIVE 3 \\ To better understand how the program was implemented and identify best practices}

The ZAMFAM program helped strengthen capacity of $\mathrm{OVC}$ and their families. Findings from the qualitative interviews and the review of program documents helped identify best practices based on innovative and unique program elements as well as document lessons learned based on challenges faced and overcome by ZAMFAM in reaching program beneficiaries.

\section{Best practices}

1. ZAMFAM's investment in trainings for community volunteers and caregivers of OVC ensured a full package for service provision for beneficiaries. CVs received training in OVC case management, which resulted in more comprehensive care and support that was tailored to match the unique needs of each OVC recruited to the program.

2. A one stop approach to program delivery ensured that beneficiaries received a wide range of services during a single visitation. As CVs conducted beneficiary home visitations, they were able to provide a variety of services to households, including health, child protection, education support and economic strengthening services. 
3. Routine meetings between program implementers and community volunteers were essential for progress review and documenting. This approach allowed for data validation for reporting as well as provided a platform to highlight core interventions to undertake in preparation for close out of the project.

4. Regular coordination meetings between ZAMFAM and other projects and government meetings were necessary for mapping stakeholders and joint planning for wellbeing of communities served. A marked benefit of the success of this collaboration with government line ministries and partners working with HIV care and treatment was that OVC under ZAMFAM were linked to HIV testing, treatment and prevention services.

5. Engaging program beneficiaries and stakeholders in the transition process is crucial for the sustainability of program interventions: transition meetings were held with parents/caregivers of OVC, CVs and key stakeholders in order to adequately plan and prepare for the sustainability of project activities after the program concluded.

6. The Families Matter! (a 5-session, evidence-based behavioral intervention designed for parents and other primary caregivers of children aged 9-12 to promote positive parenting and effective parentchild communication about sexuality and sexual risk reduction) and Faith Matters program approaches received positive feedback from the communities that implemented them as they meet the needs of adolescents and their caregivers in providing support and guidance for OVC. The programs were well received by both the OVC and their caregivers as well as the church leaders who committed to incorporating messages from the program into their biblical counseling sessions and youth health talks. Program progress reports showed that a notable number of men became more involved in parenting, reported reduced harsh and abusive parenting and skills building identifying signs of child sexual abuse.

7. The use of growth monitoring wraps (chitenge) for mothers in program communities introduced in collaboration with the Breakthrough Action project was a useful tool for empowering families (particularly mothers) in tracking growth for children under two.

\section{Lessons learned}

1. The program noted that a number of HIV positive beneficiaries do not access HIV care and treatment from the health facilities in their areas of residence. This made size estimation of HIV positive adolescents difficult in the various catchment areas. Future programs should be prepared with additional resources and personnel to account for mapping where adolescents prefer to seek services, with an understanding that they seldom do so in their residential catchment areas.

2. Despite the national guidance to test and treat, the program noted that not all new HIV positive OVC initiate ART immediately after testing due to various myths and misconceptions that were identified by implementers. Some of these misconceptions included community perceptions about taking medication only when someone becomes unwell and weak. Linkages at clinics between HIV testing and treatment services must be strengthened.

3. The community savings groups and P3 initiatives were successful in supporting household economic strengthening approaches and stability in highpoverty settings. Community programs must be designed to integrate these approaches to economic strengthening.

4. Coordination of different programs with conflicting timelines that are expected to leverage each other with regard to meeting program targets make collaboration difficult between programs. The ZAMFAM program's integration with other partners, including DREAMS, resulted in delays and lapses in program implementation resulting from their different implementation timelines.

5. Transitioning beneficiaries from predecessor programs presents challenges when partner organizations that recruited those beneficiaries are not part of the new program. Initially, the ZAMFAM program experienced delays in transitioning OVC program beneficiaries from partner organizations until cooperative agreements were signed. Future programming should prioritize engaging all relevant stakeholders as early as possible prior to implementation.

6. Community volunteers often volunteer on multiple programs which can make them over-burdened, resulting in failure to achieve program specific 
targets. The ZAMFAM program experienced this with $\mathrm{CVs}$ as they were supporting other programs being implemented in their catchment areas. Creative thought about how to incentivize volunteers and promote greater coordination between volunteerdriven programs is essential. Guidelines from government ministries on volunteer-based programs are likely necessary to ensure the sustainable future of community volunteer-based programs.

\section{Conclusion and recommendations}

The objective of the study was to explore OVC, caregiver and stakeholder perspectives on the ZAMFAM program and document best practices and lessons learned. Overall, the ZAMFAM program was viewed as having made a positive contribution to the lives of OVC by the study participants included as part of this assessment.

The study noted that exposure to and retention of messages around HIV prevention and safe sex was high amongst OVC interviewed. Stakeholders commended the collaboration between ZAMFAM implementing partners and government agencies as it was thought to ensure the sustainability of program activities beyond the life of ZAMFAM.

Based on these study findings, the following recommendations are made for future programming that focuses on OVC, caregivers of OVC and CVs.

- Programs that offer a comprehensive package of services to vulnerable households through one-stop models ensure that program beneficiaries receive the maximum benefit. However, there is need to incentivize volunteer retention throughout the life of the program to capitalize on the investments made training the volunteers.

- Low-cost, high impact interventions such as promoting local, nutritious produce promotes the sustainability of interventions. Cooking demonstrations and preservation of local food produce implemented by ZAMFAM in study sites allowed households to maximize nutritional benefit using commodities already available in their communities for the benefit of OVC households and YPLHIV.

- In managing beneficiary expectations, community programs need to clearly define and communicate support that will be provided to the beneficiaries as well as the criteria for services provided to respective households. As was the case with ZAMFAM, volunteers who often support such projects should be equipped to identify and respond to the needs of OVC utilizing referrals and linkages to other programs or activities when services are not within the project scope.

- Community savings groups have proven to be a useful approach to foster economic prosperity and resiliency at the household level. As such, future programs that introduce these models should consider providing initial capital to enable low earning communities access credit for business start-ups. However, there is need to ensure that groups are equipped to develop guidance for screening group members and managing untrustworthy members from destabilizing the group.

\section{REFERENCES}

1. Zambia Statistics Agency - ZSA, Ministry of Health $\mathrm{MOH}$, University Teaching Hospital Virology Laboratory - UTH-VL, and ICF. (2020). Zambia Demographic and Health Survey 2018. Lusaka, Zambia: ZSA, MOH, UTH-VL and ICF. Available at https://www.dhsprogram.com/pubs/pdf/FR361/FR 361.pdf.

2. XBiemba, G; Macwan'gi, M; Phiri, B; Simon, J; Costello, J; Beard, J; Brooks, B. (2009). Zambia research situation analysis of orphans and other vulnerable children: Country brief. Lusaka: Boston University Center for Global Health and Development.

3. UNAIDS. (2018). AIDSinfo. Retrieved from https://aidsinfo.unaids.org

The Population Council conducts research and delivers solutions that improve lives around the world. Big ideas supported by evidence: It's our model for global change. popcouncil.org 